\title{
From registry to quality management: the German Cystic Fibrosis Quality Assessment project 1995-2006
}

\author{
M. Stern*, B. Wiedemann\# and P. Wenzlaff on behalf of the German Cystic Fibrosis \\ Quality Assessment group
}

ABSTRACT: Since 1995, the German Cystic Fibrosis Quality Assessment project has collected demographic data and outcome parameters. It aims to develop tools for quality management.

The basic data of 6,835 patients has been collected annually by 93 centres. Weight for height and body mass index (BMI) indicated nutritional status, and forced expiratory volume in one second (FEV1) served as the central respiratory parameter. Data on mortality and survival were calculated.

The mean age of all patients has increased from 13.9 yrs in 1995 to 17.7 yrs in 2005, and the percentage of adult patients has increased from 28.4 to $43.4 \%$. Benchmarking diagrams and centre reports indicated considerable differences between the centres. The achievement of basic aims at the age of 6,12 and 18 yrs indicated a positive development in 1995 to 2005. In 2005, median age at death was 23.7 yrs and the median cumulative survival was 37.4 yrs. Mortality correlated with a BMI $<19 \mathrm{~kg} \cdot \mathrm{m}^{-2}$ and an $\mathrm{FEV} 1<80 \%$. No sex gap in mortality was detected.

"Learning from the best" is now possible. Further improvements in the system of cystic fibrosis care are required, such as: defining alarm signals for early treatment; involvement of patients and their families in quality management; auditing; benchmarking; and in-house training.

KEYWORDS: Benchmarking, centre care, cystic fibrosis, epidemiology, patient registry, quality management

entre care and the use of national and international patient registries have become essential features of healthcare and information exchange in the field of cystic fibrosis (CF) in many countries [1-7]. National registries have achieved several objectives, such as the collection of demographic data to form a basis for political action, describing the health status and mortality of CF patients, and comparing institutions involved in CF [2, 3, 8]. The most important outcome parameters used in CF in registries relate to lung function, nutritional information and microbiological findings (e.g. presence or absence of chronic infection by Pseudomonas aeruginosa). Several of these parameters have been shown to influence the general outcome indicated by mortality [1, 3, 8-10]. International registries have been used to compare differential therapeutic patterns in different countries [11, 12]. Merging national registry data into an international data pool for quality assessment and improvement ("learning from

For editorial comments see page 6 . the best") is an option currently offered by the new European Cystic Fibrosis Registry organised by the European Cystic Fibrosis Society and EuroCare CF.

In 1995, the German Cystic Fibrosis Quality Assurance (CFQA) project was initiated to build up a basic demographic database towards forming a national network of CF centres, serving as a basis for multicentre studies and for developing tools for quality management at structure, process, and outcome levels [4, 13, 14]. Assessment and description of differences between centres and also meaningful follow-up analyses of central outcome parameters in CF are now also possible. The present study aims to show that the German Cystic Fibrosis registry has evolved from a standard registry into an instrument of quality management. The German CFQA project also serves as the backbone in supporting quality assurance groups and a benchmark project. Specific evaluations, such as the development of CF-specific percentiles for key parameters for nutrition and respiratory function, are underway $[15,16]$.
AFFILIATIONS

*University of Tübingen, University Children's Hospital, Tübingen \#Technical University, Institute for Medical Informatics and Biometrics Dresden, and

"Centre for Quality and Management in Health Care, Hannover, Germany.

CORRESPONDENCE

M. Stern

University of Tübingen

University Children's Hospital

Hoppe-Seyler-Str. 1

72076 Tübingen

Germany

Fax: 497071295477

E-mail: martin.stern@med.uni-

tuebingen.de

Received:

May 092007

Accepted after revision:

August 272007

\section{SUPPORT STATEMENT}

The study was supported by the

Christiane Herzog Foundation

(Stuttgart, Germany) and

Mukoviszidose eV (Bonn, Germany).

STATEMENT OF INTEREST

None declared.
European Respiratory Journal Print ISSN 0903-1936 Online ISSN 1399-3003 


\section{METHODS}

\section{CFQA project}

The CFQA project was founded in 1995. Its overall aim is to improve quality of life and survival in CF patients. For this purpose, close cooperation was required between the $\mathrm{CF}$ centres, the CFQA scientific and executive project board, the Centre for Quality and Management in Health Care (ZQ; Hannover, Germany) and the German Cystic Fibrosis Association (Mukoviszidose e.V.; Bonn, Germany) [4, 14].

Since 1995, standardised clinical records for each patient are completed on an annual basis. They contain the relevant clinical and laboratory data. The list of variables that have been collected since 1995 include age, sex, genotype, forced vital capacity (FVC), forced expiratory volume in one second (FEV1), maximal instantaneous forced flow when $25 \%$ of the FVC remains to be exhaled (MEF25), weight, height, serum immunoglobulin G, presence or absence of P. aeruginosa and Burkholderia cepacia, as well as medical complications and therapy groups with regard to antibiotic, gastrointestinal, nutritional and respiratory treatments [4]. In step 1, lung function, nutrition, microbiology data and therapy groups are evaluated in all patients. Data taken from the routine visit near the patients' birthday, when the patient was in a stable clinical condition, were analysed [4]. Four annual outpatients' contacts per year with sputum cultures and lung function taken at every visit are a clear CFQA requirement. In step 2, a smaller group of patients are evaluated more completely and includes therapy details. Step 2 includes 18 centres with all 1,977 CF patients willing to enter all their details. Data collection is carried out electronically by the participating CF centres. First

\begin{tabular}{|c|c|c|c|}
\hline \multirow[t]{2}{*}{ TABLE 1} & \multicolumn{3}{|c|}{$\begin{array}{l}\text { Basic cystic fibrosis quality assessment data } \\
\text { from } 2005\end{array}$} \\
\hline & & Type A & Type B \\
\hline \multicolumn{2}{|l|}{ Centres $\mathbf{n}$} & 57 & 36 \\
\hline \multicolumn{2}{|c|}{ Patients median (range) } & $30(3-48)$ & $127(50-360)$ \\
\hline \multicolumn{4}{|c|}{ WH $<18$ yrs } \\
\hline \multicolumn{2}{|c|}{ Mean $\pm S D^{\#}$} & $97.9 \pm 11.8$ & $97.7 \pm 12.3$ \\
\hline \multicolumn{2}{|c|}{ Median (range) \% } & $97.1(70.5-161.5)$ & $96.5(56.0-164.4)$ \\
\hline \multicolumn{2}{|c|}{$\%$ patients with WH $>90 \%$} & 76 & 73 \\
\hline \multicolumn{4}{|c|}{ FEV $16-17$ yrs } \\
\hline \multicolumn{2}{|c|}{ Mean $\pm S D^{\#}$} & $87.0 \pm 22.9$ & $89.3 \pm 22.6$ \\
\hline \multicolumn{2}{|c|}{ Median (range) \% } & $88.7(27.0-159.2)$ & $92.5(20.1-151.4)$ \\
\hline \multicolumn{2}{|c|}{$\%$ patients with $\mathrm{FEV} 1>80 \%$} & 65.4 & 68.2 \\
\hline \multicolumn{4}{|c|}{$\mathrm{BMI} \geqslant 18 \mathrm{yrs}$} \\
\hline \multicolumn{2}{|c|}{ Mean $\pm S D^{\#}$} & $20.4 \pm 2.8$ & $20.5 \pm 2.8$ \\
\hline \multicolumn{2}{|c|}{ Median (range) } & $20.1(13.6-33.3)$ & $20.2(12.5-36.9)$ \\
\hline \multicolumn{2}{|c|}{$\%$ patients with $\mathrm{BMI}>19 \mathrm{~kg} \cdot \mathrm{m}^{-2}$} & 69.7 & 70.1 \\
\hline \multicolumn{4}{|c|}{ FEV $1 \geqslant 18$ yrs } \\
\hline \multicolumn{2}{|c|}{ Mean $\pm S D^{\#}$} & $60.0 \pm 24.4$ & $58.6 \pm 24.9$ \\
\hline \multicolumn{2}{|c|}{ Median (range) \% } & $58.8(13.9-135.0)$ & $57.5(17.8-138.4)$ \\
\hline \multicolumn{2}{|c|}{$\%$ patients with $\mathrm{FEV}_{1}>80 \%$} & 23.1 & 21.9 \\
\hline
\end{tabular}

WH: weight for height; FEV1: forced expiratory volume in one second; BMI: body mass index. \#: nonsignificant. online plausibility checks are included. For the present study, data were considered until December 31, 2005.

For the current study, aggregated data from step 1 was analysed. Weight and height data were used to calculate the predicted percentage of weight for height (WH) in children and adolescents [17] and body mass index (BMI) in adults. Patients were defined as malnourished if $\mathrm{WH}$ was $<90 \%$ of the predicted references for sex and height in children, or if the BMI was $<19 \mathrm{~kg} \cdot \mathrm{m}^{-2}$ in adults [17-19]. Pulmonary function was considered abnormal if FEV1 was $<80 \%$ of the predicted reference value $[20,21]$. Further parameters of pulmonary function were entered into the database but were not used in the present study. The references were based on the recommendations made by the Scientific Advisory Committee of the CFQA project. Specific percentiles for WH, BMI and FEV1 were calculated for children and adolescents with CF [15].

\section{Database and statistical analysis}

In order to guarantee data protection, each patient was assigned a unique pseudonym. Written informed consent was obtained from the parents and/or patients.

Cross-sectional and longitudinal analyses were carried out. Patients were grouped according to the risk factors present, such as malnutrition, subnormal lung function and infection by $P$. aeruginosa. Benchmarking data were grouped with respect to centres, i.e. type A (1-49 patients) and type B ( $\geqslant 50$ patients).

The clinical records collected by the CF centres were sent to the ZQ (Hannover) where they were stored in a central database, administered and managed. Additional plausibility checks were integrated to identify and to eliminate incomplete, incorrect, inconsistent and missing data as well as to avoid multiple storage of data records. For the analysis of outcome variables, values were defined within the targeted range of quality $\left(\mathrm{WH} \geqslant 90 \%\right.$, BMI $\geqslant 19 \mathrm{~kg} \cdot \mathrm{m}^{-2}, \mathrm{FEV} 1 \geqslant 80 \%$, as previously discussed). An unpaired t-test was used when comparing the groups. The means of more than two different

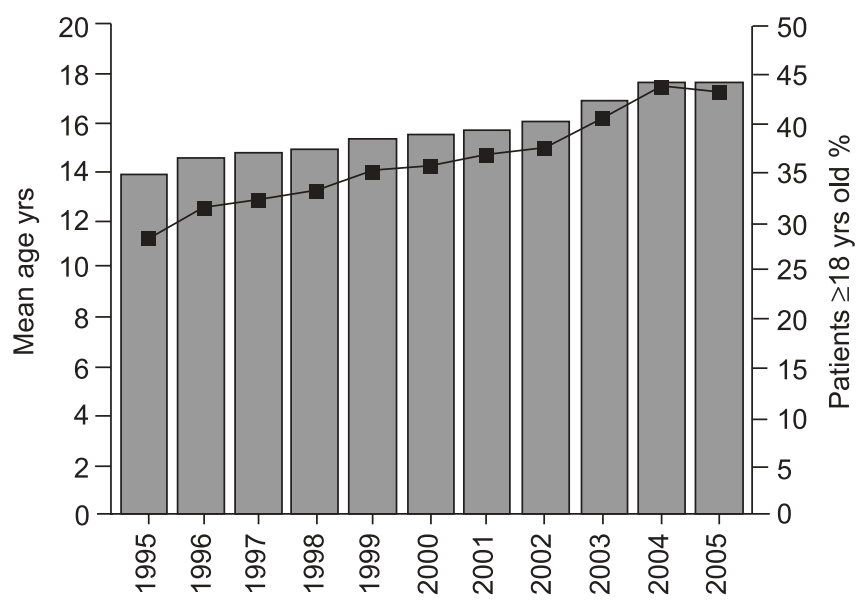

FIGURE 1. Mean age $(\square)$ and percentage of cystic fibrosis patients aged $\geqslant 18 \mathrm{yrs}$ and $(\boldsymbol{\square})$ annually reported to the cystic fibrosis quality assessment project. The number of subjects enrolled in each study year, from 1995 to 2005 consecutively, was as follows: $n=2,496 ; n=3,070 ; n=3,473 ; n=3,796 ; n=3,855$ $n=3,881 ; n=3,972 ; n=4,098 ; n=4,373 ; n=4,520 ; n=4,551$. 


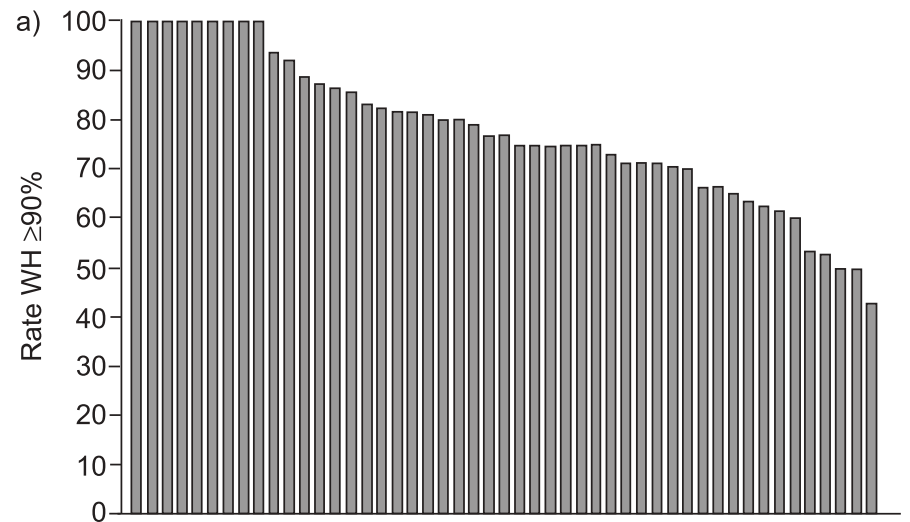

b)

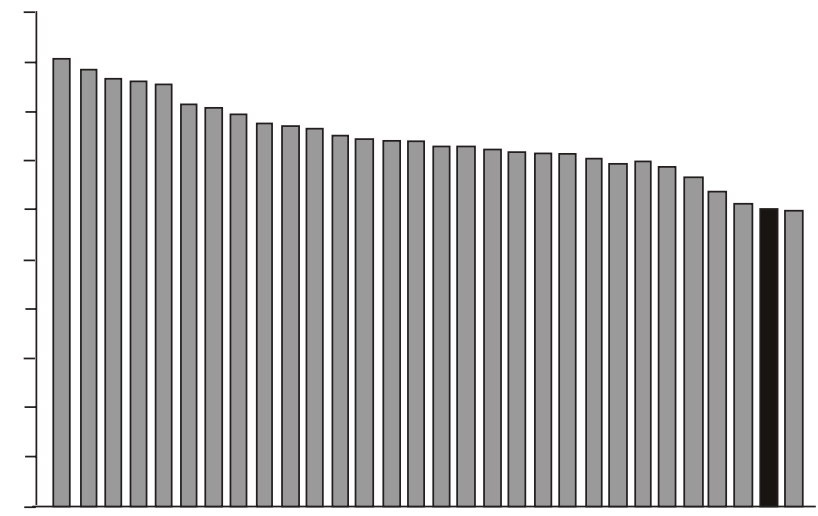

c)

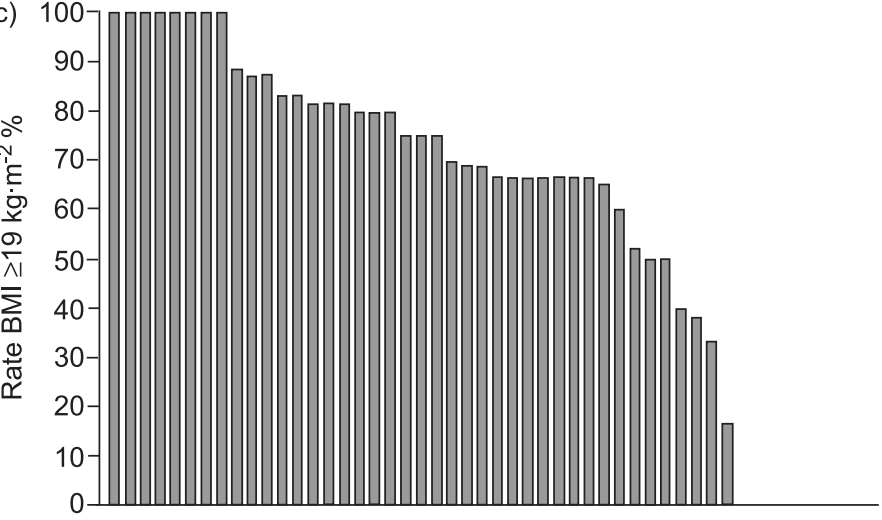

Type A CF centres d)

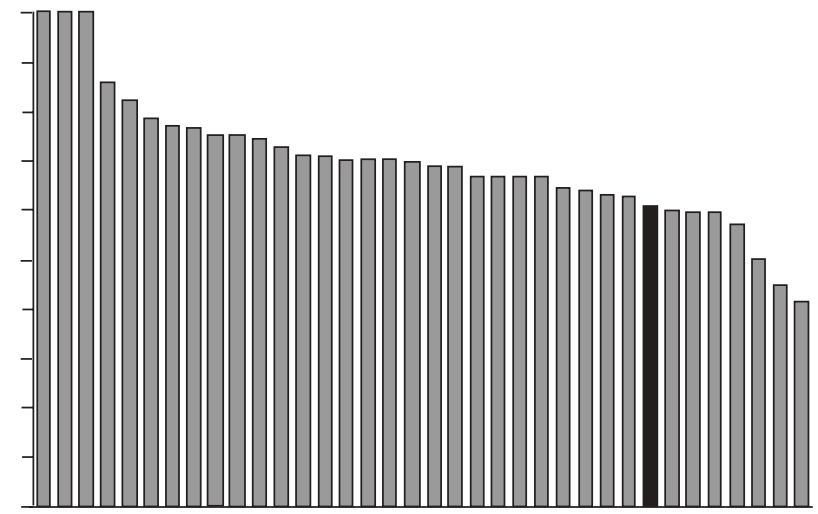

Type B CF centres

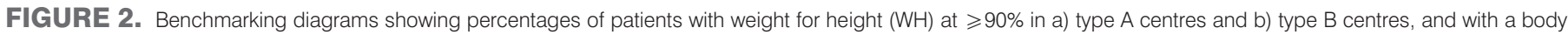

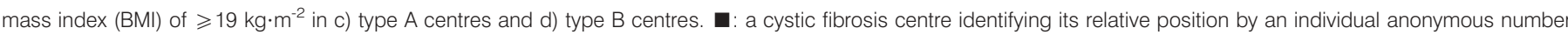
exclusively known to the centre.

groups were compared using parametric or nonparametric analysis of variance. The Chi-squared test was used to determine differences between groups with regard to the frequencies of certain variables. A p-value $<0.05$ was considered statistically significant. For the determination of cumulative survival, the method described by WARWICK et al. [22] was used. For evaluation of risk factors at 18 yrs of age, the survival analysis by Kaplan-Meier was used. With regard to the completeness of data analysed, the rate of missing data was low (e.g. $0.1 \%$ for weight and height, $0.3 \%$ for bacteriology, $2.6 \%$ for FEV1 [14]).

\section{RESULTS}

\section{Basic data in CF centres}

From 1995 to 2005, 6,835 patients were treated at 93 centres in Germany. Only 36 of those centres treated $\geqslant 50$ patients (type B). Of these, 14 treated $>100$ patients and $39.7 \%$ of adult patients were treated in one of 13 adult CF centres. The remaining adult patients were treated in paediatric or mixed $\mathrm{CF}$ centres. The annual data records of 4,551 patients were returned in 2005. After subtracting the number of patients who had died as well as the patients who did not give informed consent $(n=130)$, the annual return rate for 2005 was $73.4 \%$. This figure has improved to $82 \%$ by late data delivery. Detailed analysis of late data showed no difference in sex, age and disease severity to the data submitted on time. Table 1 indicates basic data, such as the number of patients and central nutritional and lung function data, with regard to type $A$ and B centres (no statistically significant differences found).

Figure 1 shows the mean age and percentage of adult patients annually reported to the CFQA between 1995 and 2005. The figures are exclusively based on the annual return of data and show an increase in numbers in comparison to participation at the beginning of the project. Since 1995, mean age has increased from 13.9 to $17.7 \mathrm{yrs}$, and the percentage of adult patients has increased from 28.4 to $43.4 \%$. However, these descriptive data do not indicate the specific factors that primarily contributed to this positive development. A plateau has evidently been reached since 2004 .

\section{Benchmarking diagrams and centre reports: follow-up reports}

The nutritional and lung function data of the CFQA project are given as benchmarking diagrams. This means that each $\mathrm{CF}$ centre (type A: $1-49$ patients; type $\mathrm{B}: \geqslant 50$ patients) is represented by an individual bar, depending on the percentages of values reached for WH, BMI and FEV1 (figs 2 and 3). Thus, a given CF centre can only identify its own relative position by an individual anonymous number exclusively known to this centre. One specific CF centre that consented to this procedure has been documented in figs 2 and 3. This analysis can also serve as a starting point for identifying 


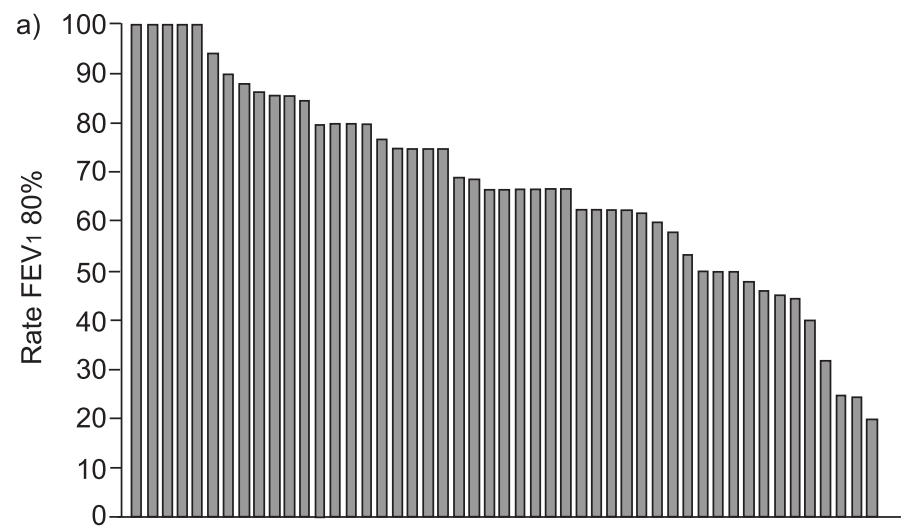

b)
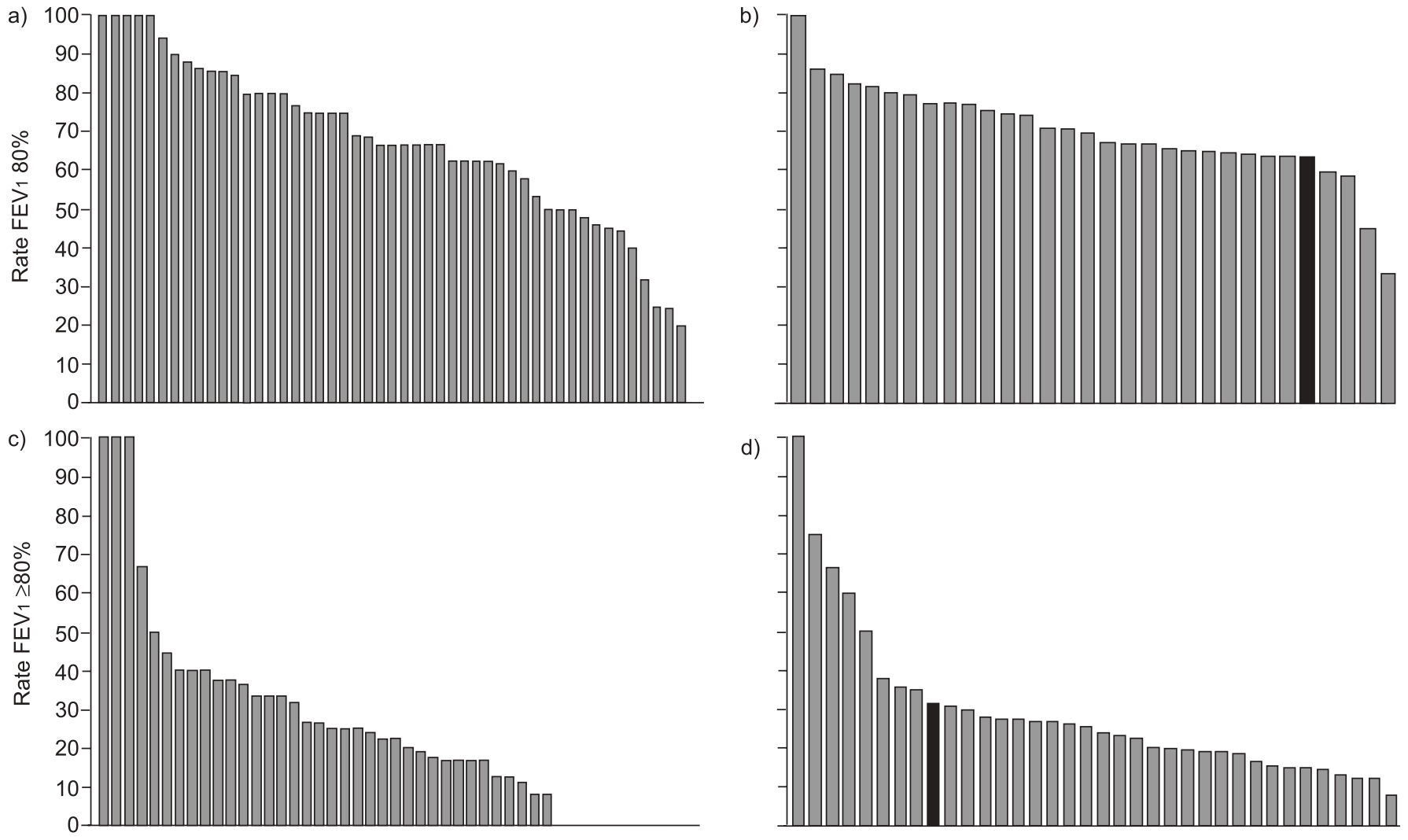

Type A CF centres d)

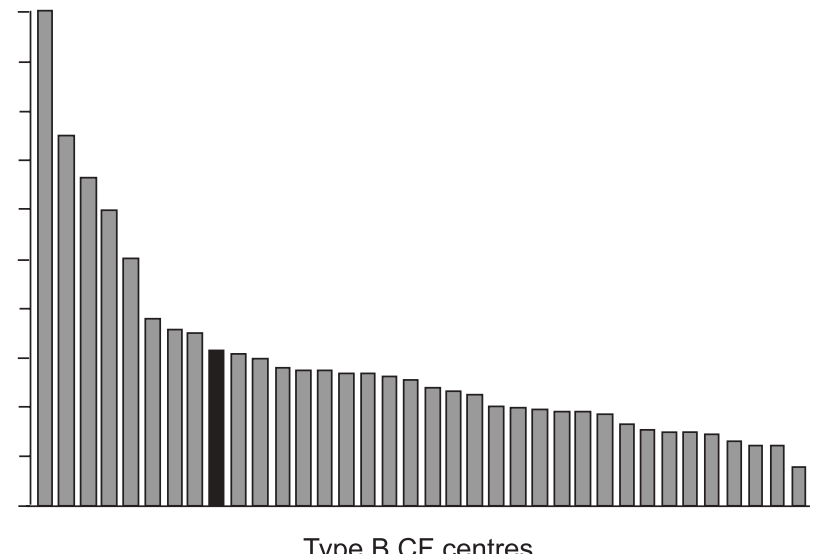

FIGURE 3. Percentages for forced expiratory volume in one second ( $\left.F E V_{1}\right)$ at $\geqslant 80 \%$ in patients aged $6-17$ yrs in a) type $A$ centres and b) type B centres, and in patients aged $\geqslant 18$ yrs in c) type $A$ centres and d) type B centres. : a cystic fibrosis centre identifying its relative position by an individual anonymous number exclusively known to the centre.

differences in therapeutic strategies. In addition, centres producing the best possible values can be identified. It must be noted that a wide variability of outcome data was found in the case of smaller CF centres. Major differences are evident in the benchmark diagrams. These diagrams are part of the general annual report through which centre directors can only identify their own relative position. In addition to this general report, an individual centre report is issued to all participants. This enables the centre director to select patients with particularly remarkable results and to decide on individual measures.

One way to achieve better quality management is used for long-term follow-up, in which given parameter percentages are compared, as shown in table 2 for CF patients aged 6,12 and 18 yrs. Table 2 provides evidence that improvement was achieved across all age groups. However, the aims set for WH and FEV1 could not be reached and the absence of $P$. aeruginosa was more frequent in all age groups in 2005 as compared with 1995. This was probably due to earlier and more aggressive antibiotic treatment [23].

\section{Mortality data}

Mortality is considered the final outcome measure (fig. 4). Figure 4a shows the age distribution of patients who died between 1995 and 2005. From 1995 to 2005, the median age at death increased from 18.5 to 23.7 yrs. In $2005,17.6 \%$ of all CF patients who died were $<18$ yrs of age. The rate of mortality was $1.1 \%$ for all patients observed in 2005. Cumulative survival was also analysed (fig. 4 b). With a confidence interval (CI) of $95 \%$, the median length of survival was $37.4 \mathrm{yrs}$ in Germany. The $95 \%$ CI was relatively broad after $30 \mathrm{yrs}$ of age. The probability of a patient reaching $40 \mathrm{yrs}$ of age was $59 \%$ with a $95 \%$ CI of $45-74 \%$. This figure has increased gradually from 1995 to 2005.

Survival analysis was also carried out for each patient group by taking into account risk factors, such as a BMI $<19 \mathrm{~kg} \cdot \mathrm{m}^{-2}$, FEV1 $<80 \%$ and P. aeruginosa infection (fig. 5). Only patients aged 17-19 yrs during 1995 are depicted. The data are based on: 45 out of 112 patients with low BMI in 1995 who had died by the end of 2005 (fig. 5a); 46 out of 146 patients who had died and who had a low FEV1 (fig. 5b); and 44 out of 155 patients with $P$. aeruginosa infection who had died (fig. 5c). Only low BMI and low FEV1 showed statistically significant differences compared with the controls $(\mathrm{p}<0.01)$.

\section{DISCUSSION}

The German CFQA project has set up a basic CF registry with data from 6,835 patients treated in Germany between 1995 and 2005 [14]. These patients were treated at 93 centres with varying capacities. In comparison to North American and Scandinavian countries, these centres are relatively small. Conversely, cooperation and shared care became necessary 


\begin{tabular}{|c|c|c|c|c|c|}
\hline TABLE 2 & $\begin{array}{l}\text { Developm } \\
\text { the aims } \\
\text { assessme }\end{array}$ & $\begin{array}{l}\text { ent of } \\
\text { et by } \\
\text { it in }\end{array}$ & $\begin{array}{l}\text { cal pa } \\
\text { c fibrc } \\
-2005\end{array}$ & $\begin{array}{l}\text { ters in } \\
\text { (CF) q }\end{array}$ & tion to \\
\hline \multirow{2}{*}{\multicolumn{2}{|c|}{ Parameters }} & \multirow[t]{2}{*}{ Aim } & \multicolumn{3}{|c|}{ Status } \\
\hline & & & 1995 & 2000 & 2005 \\
\hline \multicolumn{6}{|c|}{ CF patients aged 6 yrs } \\
\hline Subjects $n$ & & & 113 & 144 & 145 \\
\hline$W H \geqslant 95 \% p$ & red & 100 & 60.2 & 61.8 & 56.6 \\
\hline $\mathrm{FEV}_{1} \geqslant 80 \%$ & pred & 100 & 74.7 & 77.2 & 80.3 \\
\hline P. aeruginosa & negative \% & 80 & 56.6 & 71.8 & 82.8 \\
\hline \multicolumn{6}{|c|}{ CF patients aged 12 yrs } \\
\hline Subjects $n$ & & & 108 & 159 & 180 \\
\hline$W H \geqslant 95 \% p$ & red & 100 & 47.2 & 46.5 & 48.3 \\
\hline $\mathrm{FEV}_{1} \geqslant 80 \%$ & pred & 80 & 53.7 & 59.7 & 56.1 \\
\hline P. aeruginose & negative \% & 60 & 35.2 & 51.3 & 50.3 \\
\hline \multicolumn{6}{|c|}{ CF patients aged 18 yrs } \\
\hline Subjects $n$ & & & 72 & 125 & 152 \\
\hline$W H \geqslant 95 \% p$ & red & 100 & 45.8 & 64.8 & 67.8 \\
\hline $\mathrm{FEV}_{1} \geqslant 80 \%$ & pred & 70 & 22.2 & 25.8 & 32.5 \\
\hline$P$. aeruginosa & negative \% & 30 & 23.6 & 37.8 & 39.3 \\
\hline
\end{tabular}

WH: weight for height; \% pred: \% predicted; FEV1: forced expiratory volume in one second; $P$. aeruginosa: Pseudomonas aeruginosa.

and enhanced the project. There is good comparison of the data on mean age and percentage of adult patients with data from published reports of other national registries [5-7]. Data of higher survival and age have been observed in countries that have national CF registries. However, conclusions cannot yet be drawn with regard to the factors involved in this development, some of which may well be related to changes in CF care or therapeutic strategies. Over the last few years, the current authors' data has shown that age development has reached a plateau in Germany.

Through the project, descriptive information is now available on demography, diagnosis, genotype, social information, complications, therapy groups and decisive outcome parameters related to respiratory function, nutrition and microbiology. The present study focuses on the following parameters: WH (\% pred), BMI $\left(\mathrm{kg} \cdot \mathrm{m}^{-2}\right), \mathrm{FEV} 1(\%$ pred $)$ and infection status regarding $P$. aeruginosa (absence/presence). These data have also been analysed and serve as tools for quality management, particularly as benchmarking diagrams $[6,24,25]$. On the grounds of consistency and long-term follow-up, WH was taken to indicate malnutrition in children and adolescents. However, it must be noted that BMI is a more precise parameter even for younger children $[15,16,19]$. In the future, BMI based on percentiles for children and adolescents will be applied in the German CFQA project [13, 16, 18, 19].

In the present study, differences between centres (type A: 1-49 patients; type $\mathrm{B}: \geqslant 50$ patients) are indicated by the percentage of patients with $\mathrm{WH}>90 \%$ (children), BMI $>19 \mathrm{~kg} \cdot \mathrm{m}^{-2}$ (adults) and FEV1 $>80 \%$ (figs 2 and 3 ). Considerable variance was observed in Germany, particularly among the smaller centres. These differences ranged: $\sim 40-100 \%$ for the rate of acceptable $\mathrm{WH} ; 20-100 \%$ for $\mathrm{BMI} \geqslant 19 \mathrm{~kg} \cdot \mathrm{m}^{-2} ; 20-100 \%$ for the rate of FEV $1 \geqslant 80 \%$ in children and adolescents; and $<10-100 \%$ in the percentage of $\mathrm{FEV} 1 \geqslant 80 \%$ in adult CF patients. While there was no difference in disease severity between type A and B centres in terms of age, age at diagnosis and sex, selection bias cannot be excluded. An open comparison between centres can be made once a consensus is reached between members of the German project $[14,15]$. Benchmarking diagrams are valuable for identifying best practice or specific drawbacks in care centres, as well as therapeutic strategies. Several auditing and quality groups have been created in Germany to enable $\mathrm{CF}$ centres to learn from the best. It is crucial to establish a highly developed system of care promoting early and aggressive multilevel treatment, as well as involving patients and their families in quality management programmes [11, 12, 23, 25]

Clearly, the ultimate outcome variable in CF is mortality. Many factors, such as malnutrition, early decrease of respiratory function and chronic infection by $P$. aeruginosa play an important role in the outcome [10, 24, 26, 27] and their influence is obviously interrelated $[9,13,24,27]$. The crucial importance of follow-up during childhood is obviously related
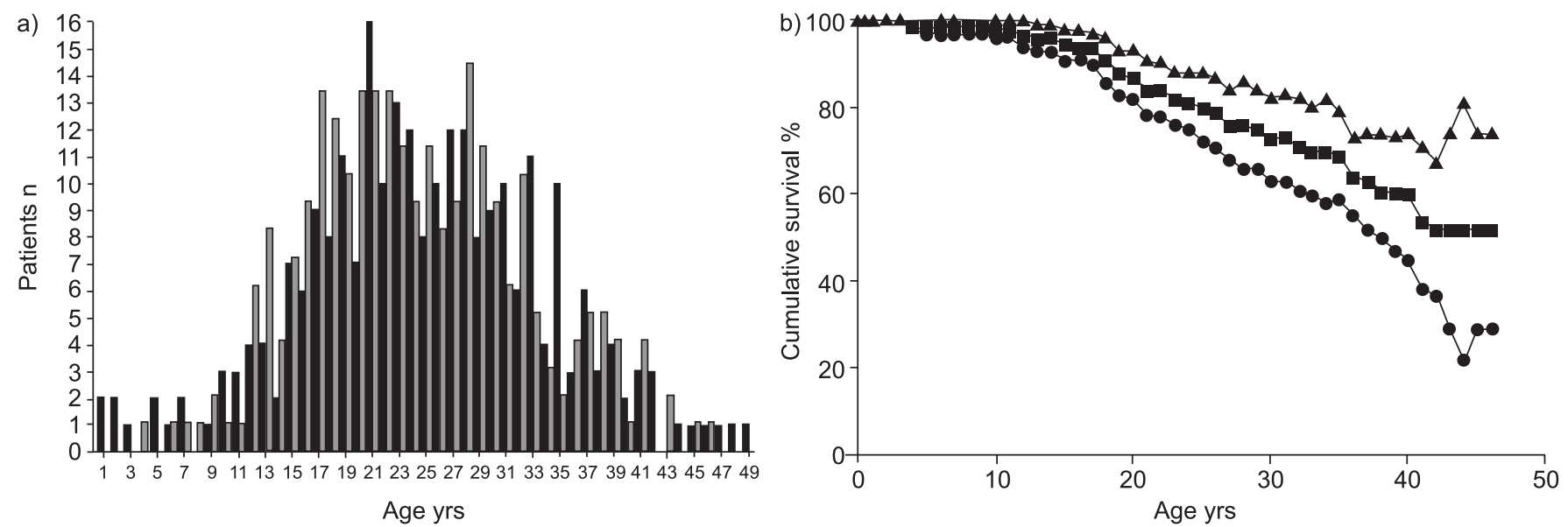

FIGURE 4. a) Age at death between 1995 and 2005. male $(n=256) ; \quad$ : female $(n=251)$. b) Cumulative survival and $95 \%$ confidence interval in 2005 : lower limit of confidence interval $(\mathrm{Cl})$; median $\mathrm{Cl} ;$ upper limit of $\mathrm{Cl}$ 

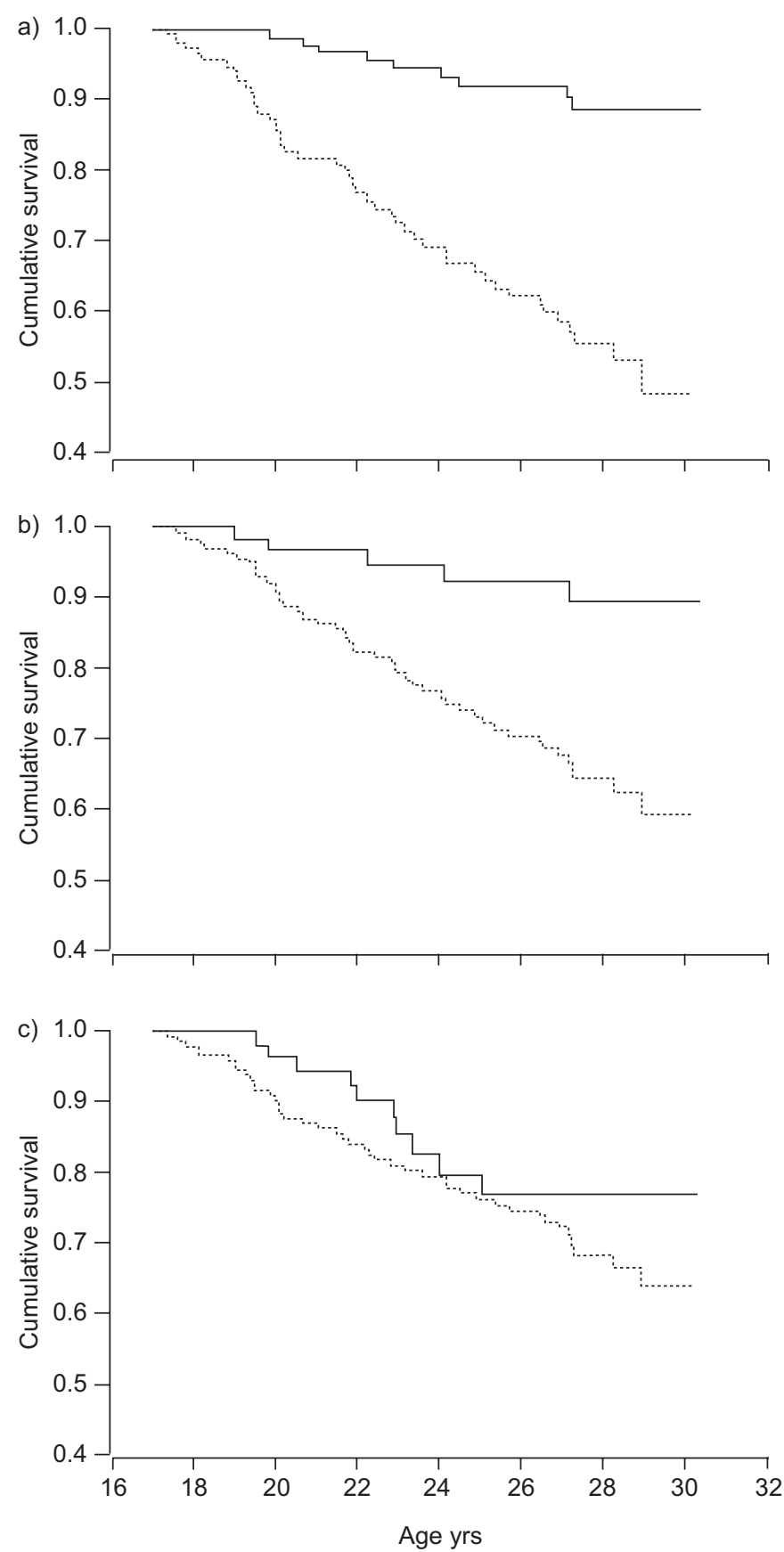

FIGURE 5. Cumulative survival (1995-2005) versus age in cystic fibrosis patients in 1995 in relation to a) body mass index (BMI), b) forced expiratory volume in one second (FEV1), and c) Pseudomonas aeruginosa. a) —: BMl $\geqslant 19 \mathrm{~kg} \cdot \mathrm{m}^{-2}$ $\left.(n=112) ; \cdots \cdot \mathrm{BMI}<19 \mathrm{~kg} \cdot \mathrm{m}^{-2}(\mathrm{n}=106) ; \mathrm{b}\right)-\mathrm{FEV} 1 \geqslant 80 \%(\mathrm{n}=146) ; \cdots \cdot \mathrm{FEV} 1$ $<80 \%(n=65) ; c)-$. $P$. aeruginosa negative $(n=155) ; \cdots: P$. aeruginosa positive $(n=61)$.

to the fact that this phase represents the time in which preventive measures can be applied, and early, aggressive therapy can be initiated before irreversible impairment occurs. The mortality statistics for the German CFQA project are similar to those of international groups. Median age at death was 23.7 yrs in 2005. This also applies to the positive trend in the follow-up of mortality rates, and CF is, in fact, no longer an important cause of death during childhood [28] in Germany. However, in 2005, there were nine CF patients $<18$ yrs of age who died in Germany.

Interestingly, there was no sex gap or difference in survival curves among the female and male patients studied (data not shown). The median cumulative length of survival [14, 22] was 37.4 yrs, with a relatively broad $95 \%$ CI. This compares well with data from France and the USA [6,7]. The current analysis of individual factors and early predictors of mortality showed that BMI and FEV1 were predictive [10, 16, 27, 28]. These statistics are valuable in defining alarm signals for early aggressive treatment and also for establishing definition referral criteria for lung transplant [27]. However, it must be mentioned that some cases lost to follow-up in the present study included patients who had not been treated by $\mathrm{CF}$ centres prior to their death. Thus, in-depth analyses of mortality data are necessary and corrections should be made where appropriate.

Quality management is now a major tool in CF care centres [29, 30]. It is maintained by national registries, such as the German CFQA project, which analyse data and develop tools for individual centres and quality groups for the purposes of identifying best practice, learning from the best and continuing improvement of CF care. In the future, the descriptive instruments described here should be used for the differential evaluation of CF therapy. Many lessons have been learned from the CFQA project: reinforcement of centre compliance by direct financial support; direct benefit in quality management concerning centre reports; individual follow-up graphs; telephone queries; personal contact; formation of quality groups; the benchmarking project; and, last but not least, the improvement of the software system used.

Auditing and in-house training are further steps to speed up quality improvement. The analysis of data could lead to the certification of cystic fibrosis centres as well as to the guided planning of structures and strategies in cystic fibrosis care. It could also serve as a basis for political action in the healthcare system and for improvements in quality awareness at all levels (individual, centres, quality groups, political, charity institutions). Only long-term application of quality management in cystic fibrosis will be appropriate to improve overall coverage (now $82 \%$ for the year of 2005). Thus, national, the Cystic Fibrosis Quality Assessment project, and international cooperation contribute to the process of improving subspecialty healthcare in cystic fibrosis in significant ways [24].

\section{ACKNOWLEDGEMENTS}

The authors would like to thank all participants from the 93 cystic fibrosis centres who contributed data to the project.

\section{REFERENCES}

1 Corey M, McLaughlin FJ, Williams M, Levison $\mathrm{H}$. A comparison of survival, growth, and pulmonary function in patients with cystic fibrosis in Boston and Toronto. J Clin Epidemiol 1988; 41: 583-591.

2 FitzSimmons SC. The changing epidemiology of cystic fibrosis. J Pediatr 1993; 122: 1-9. 
3 Dodge JA, Morison S, Lewis PA, et al. Incidence, population, and survival of cystic fibrosis in the UK, 1968-95. Arch Dis Child 1997; 77: 493-496.

4 Wiedemann B, Steinkamp G, Sens B, Stern M, for the German Cystic Fibrosis Quality Assurance Group. The German cystic fibrosis quality assurance project: clinical features in children and adults. Eur Respir J 2001; 17: 1187-1194.

5 McCormick J, Sims EJ, Green MW, Mehta G, Culross F, Mehta A. Comparative analysis of Cystic Fibrosis Registry data from the UK with USA, France and Australasia. J Cyst Fibr 2005; 4: 115-122.

6 Cystic Fibrosis Foundation Patient Registry Annual Data Report 2005. www.cff.org/UploadedFiles/research/ ClinicalResearch/PatientRegistryReport/2005\%20Patient $\%$ 20Registry\%20Report.pdf Date last accessed: October 5, 2007.

7 The French National Cystic Fibrosis Observatory (ONM). Report on 2004 data. Paris, Vaincre la Mucoviscidose and INED, 2006.

8 Corey M, Farewell V. Determinants of mortality from cystic fibrosis in Canada, 1970-1989. Am J Epidemiol 1996; 143: 1007-1017.

9 Zemel BS, Jawad AF, FitzSimmons S, Stallings VA. Longitudinal relationship among growth, nutritional status, and pulmonary function in children with cystic fibrosis: analysis of the Cystic Fibrosis Foundation National CF Patient Registry. J Pediatr 2000; 137: 374-380.

10 Sharma R, Florea VG, Bolger AP, et al. Wasting as an independent predictor of mortality in patients with cystic fibrosis. Thorax 2001; 56: 746-750.

11 Koch C, McKenzie SG, Kaplowitz H, et al. International practice patterns by age and severity of lung disease in cystic fibrosis: data from the Epidemiologic Registry of Cystic Fibrosis (ERCF). Pediatr Pulmonol 1997; 24: 147-154.

12 Morgan WJ, Butler SM, Johnson CA, et al. Epidemiologic study of cystic fibrosis: design and implementation of a prospective, multicenter, observational study of patients with cystic fibrosis in the U.S. and Canada. Pediatr Pulmonol 1999; 28: 231-241.

13 Steinkamp G, Wiedemann B, on behalf of the German CFQA Group, Relationship between nutritional status and lung function in cystic fibrosis: cross sectional and longitudinal analyses from the German CF quality assurance (CFQA) project. Thorax 2002; 57: 596-601.

14 Stern M, Sens B, Wiedemann B, Busse O, Damm G, Wenzlaff P, eds. Qualitätssicherung Mukoviszidose 2005 Überblick über den Gesundheitszustand der Patienten in Deutschland 2005. [CF quality assurance in Germany: data from 2005.] Medizinisch Wissenschaftliche Berlin, Verlagsgesellschaft, 2006.

15 Stern M, Sens B, Wiedemann B, Busse O, Damm G, Wenzlaff $\mathrm{P}$, eds. Qualitätssicherung Mukoviszidose: Überblick über den Gesundheitszustand der Patienten in
Deutschland 2004. [CF quality assurance in Germany: data from 2004.] Bonn, Verlag Schöneseifen, 2005.

16 Wiedemann B, Paul KD, Stern M, Wagner TO, Hirche TO, on behalf of the German CFQA Group. Evaluation of body mass index percentiles for assessment of malnutrition in children with cystic fibrosis. Eur J Clin Nutr 2007; 61: 759-768.

17 Reinken L, Van Oost G. Longitudinale Körperentwicklung gesunder Kinder von 0 bis 18 Jahren. [Longitudinal physical development of healthy children 0 to 18 years of age. Body length/height, body weight and growth velocity.] Klin Pädiatr 1992; 204: 129-133.

18 Kromeyer-Hauschild K. Perzentile für den body-massindex für das kindes- und jugendalter unter heranziehung verschiedener deutscher stichproben. [Percentiles of body mass index in children and adolescents evacuated from different regional German studies.] Monatsschr Kinderh 2001; 149: 807-818.

19 Lai HJ. Classification of nutritional status in cystic fibrosis. Curr Opin Pulm Med 2006; 12: 422-427.

20 Quanjer PH. Standardized lung function testing. Report Working Party "Standardization of Lung Function Tests". Bull Eur Physiopathol Respir 1983; 19: Suppl. 5, S1-S95.

21 Zapletal A, Samanek M, Paul T. Lung Function in Children and Adolescents. (Progress in Respiratory Research). Basel, Karger, 1987.

22 Warwick WJ, Pogue RE, Gerber HU, Nesbitt CJ. Survival patterns in cystic fibrosis. J Chronic Dis 1975; 28: 609-622.

23 Frederiksen B, Lanng S, Koch C, Høiby N. Improved survival in the Danish centre treated cystic fibrosis patients: results of aggressive treatment. Pediatr Pulmonol 1996; 21: 153-158.

24 O'Connor GT, Quinton HB, Kahn R, et al. Case-mix adjustment for evaluation of mortality in cystic fibrosis. Pediatr Pulmonol 2002; 33: 99-105.

25 Schechter MA, Margolis P. Improving subspecialty healthcare: lessons from cystic fibrosis. J Pediatr 2005; 147: 295-301.

26 Emerson J, Rosenfeld M, McNamara S, Ramsey B, Gibson RL. Pseudomonas aeruginosa and other predictors of mortality and morbidity in young children with cystic fibrosis. Pediatr Pulmonol 2002; 34: 91-100.

27 Mayer-Hamblett N, Rosenfeld M, Emerson J, Goss CH, Aitken ML. Developing cystic fibrosis lung transplant referral criteria using predictors of 2-year mortality. Am J Respir Crit Care Med 2002; 166: 1550-1555.

28 Dodge JA, Lewis PA, Stanton M, Wilsher J. Cystic fibrosis mortality and survival in the UK: 1947-2003. Eur Respir J 2007; 29: 523-526.

29 Kerem E, Conway S, Elborn S, Heijerman H. Standards of care for patients with cystic fibrosis: a European consensus. J Cyst Fibr 2005; 41: 7-26.

30 Mahadeva R, Webb K, Westerbeek RC, et al. Clinical outcome in relation to care in centres specialising in cystic fibrosis: cross sectional study. BMJ 1998; 316: 1771-1775. 